\title{
Lidar Remote Sensing for Biomass Assessment
}

\author{
Jacqueline Rosette1,3,4, Juan Suárez 2,4, Ross Nelson³, \\ Sietse Los ${ }^{1}$, Bruce Cook ${ }^{3}$ and Peter North ${ }^{1}$ \\ ${ }^{1}$ Swansea University, \\ ${ }^{2}$ Forest Research \\ ${ }^{3}$ NASA Goddard Space Flight Center, \\ ${ }^{4}$ University of Maryland College Park \\ 1,2United Kingdom \\ 3,4 USA
}

\section{Introduction}

Optical remote sensing provides us with a two dimensional representation of land-surface vegetation and its reflectance properties which can be indirectly related to biophysical parameters (e.g. NDVI, LAI, fAPAR, and vegetation cover fraction). However, in our interpretation of the world around us, we use a three-dimensional perspective. The addition of a vertical dimension allows us to gain information to help understand and interpret our surroundings by considering features in the context of their size, volume and spatial relation to each other.

In contrast to estimates of vegetation parameters which can be obtained from passive optical data, active lidar remote sensing offers a unique means of directly estimating biophysical parameters using physical interactions of the emitted laser pulse with the vegetation structure being illuminated. This enables the vertical profile of the vegetation canopy to be represented, not only permitting canopy height, metrics and cover to be calculated but also enabling these to be related to other biophysical parameters such as biomass.

This chapter provides an overview of this technology, giving examples of how lidar data have been applied for forest biomass assessment at different scales from the perspective of satellite, airborne and terrestrial platforms. The chapter concludes with a discussion of further applications of lidar data and a look to the future towards emerging lidar developments.

\subsection{Context}

Aside from destructive sampling, traditional methods of calculating biomass for forest inventory, monitoring and management often rely on taking field measurements within sample plots, such as diameter at breast height (DBH) or Top/Lorey's height. This effort can be time, cost and labour intensive. Extrapolation of field measurements to larger areas relies on representative sampling of trees within a land-cover type and correct classification of land cover over large areas; both of which have inherent uncertainties.

Lidar remote sensing complements traditional field methods through data analysis which enables the extraction of vegetation parameters that are commonly measured in the field. 
Additionally, establishing allometric relationships between lidar and field measurements enables estimates to be extrapolated to stand, forest or national scales, which would not be feasible or very costly using field survey methods alone. Key aspects of biomass estimation from satellite, airborne and terrestrial lidar systems are outlined below.

\subsection{Principles of lidar remote sensing}

When walking through a woodland on a sunny day, some of the sunlight reaches the ground through gaps between the foliage, woody branches and stems; some produces more diffuse light at the ground by transmittance though the foliage or reflection between different vegetation components and the ground, and some is absorbed by the intercepted surfaces. A proportion of the energy is reflected from these surfaces back towards the source. The same principles apply to lidar.

Lidar (Light Detection and Ranging) is an active remote sensing technology, which involves the emission of laser pulses from the instrument positioned on a platform, towards a target (e.g. woodland). Here, it interacts with the different surfaces it intercepts as outlined above (Figure 1). Features further from the sensor will intercept and reflect the laser energy back to the sensor later than those closer to it.

The area which is illuminated by the laser pulse is known as the lidar 'footprint'. The size of the footprint is determined by the laser divergence and the altitude/distance from the target of the lidar instrument. Whether the footprint is of large dimensions in the region of tens of metres from the altitude of a satellite sensor, tens of centimetres as generally produced from airborne platforms or several millimetres in the case of terrestrial laser scanners, the principles remain the same.

Interactions of the laser pulse with the vegetation depend on the wavelength of the emitted pulse and its reflectance, transmittance and absorption rates for each foliage, bark and background type (e.g. bare soil, litter, snow, etc). At wavelengths of $1064 \mathrm{~nm}$ (in the nearinfrared region of the spectrum and typical of many lidar systems used for vegetation analysis), reflectance and transmittance values may each be commonly $\sim 45 \%$.

The time for the reflected pulse echoes to be returned to the sensor is measured and, using the fact that the laser pulse travels at the speed of light, the total return distance travelled between the sensor and the intercepted surfaces can be calculated. The distance between the altimeter and the intercepted object is therefore half of this value (Baltsavias, 1999; Wehr et al., 1999). This permits the three-dimensional reproduction of the Earth surface relief and above-surface object structures (e.g. vegetation, ice cover, atmospheric aerosols and cloud structure).

Very accurate timing is necessary to obtain fine vertical resolutions. Lidar time units are generally recorded in nanoseconds (ns), each being equal to approximately $15 \mathrm{~cm}$ in one-way distance between the sensor and target. Time is measured by a time interval counter, initiated on emission of the pulse and triggered at a specific point on the leading edge of the returned pulse. This position is not immediately evident and therefore is set to occur where the signal voltage reaches a pre-determined threshold value. The steepness of the received pulse (rise time of the pulse) is a principal contributory factor to range accuracy and depends on the combination of numerous factors such as incident light wavelength, reflectivity of targets at that wavelength, spatial distribution of laser energy across the footprint and atmospheric attenuation (Baltsavias, 1999). The return pulse leading edge rise time is therefore formed by the strength of the return signal from the highest intercepted 
surfaces within the footprint. This will vary with the nature of the surface; flat ice sheets producing abrupt returns with fast leading edge rises and multilayered, complex vegetation creating broad returns (Harding et al., 1998; Ni-Meister et al., 2001).



Fig. 1. Representation of the interception of foliage, bark or ground surfaces by an emitted laser pulse. At each surface, some energy is reflected, transmitted (in the case of foliage) or absorbed.

The location of every returned signal to a known coordinate system is achieved by precise kinematic positioning using differential GPS and orientation parameters by the Inertial Measurement Unit (IMU). The IMU captures orientation parameters of the instrument platform such as pitch, roll and yaw angles. Therefore, the GPS provides the coordinates of the laser source and the IMU indicates the direction of the pulse. With the ranging data accurately measured and time-tagged by the clock, the position of the returned signal can be calculated.

\subsection{Full waveform and discrete return systems}

A waveform is the signal that is returned to the lidar sensor after having been scattered from surfaces that the laser pulse intercepts. Full waveform lidar systems record the entire returned signal within an elevation range window above a background energy noise threshold. An example of this from NASA's Geoscience Laser Altimeter System (GLAS; Section 2) is shown in Figure 2 (left). The scene shows a two-storey Douglas Fir canopy (Pseudotsuga menziesii) on a gentle slope of $4.9^{\circ}$. Typically, for vegetated surfaces on relatively flat ground, a bimodal waveform is produced. 
The beginning and end of the waveform signal above the background noise threshold are represented by the upper and lower horizontal blue lines respectively (mean noise $+4.5 \sigma$ in the case of GLAS). Amplitude of the waveform ( $x$ axis) represents both intercepted surface area at each elevation plus the reflectivity of the surfaces at the emitted wavelength (1064nm).

The gradient at the beginning of the signal increases slowly initially due to the relatively small surface area of foliage and branch elements at the uppermost canopy. As the energy penetrates down through the canopy, the waveform amplitude increases as more features are intercepted, before decreasing towards the base of the tree crowns. A small peak, which corresponds to a shorter tree, can be observed above the abrupt, narrow peak, which is returned from the ground. Below the ground surface, the signal can be seen to trail off gradually. This relates to both a gentle slope found at this site plus the effect of multiple scattering between features within the scene, which serves to delay part of the signal that is returned to the sensor.

Due to the complex waveform signal which is produced, this is often simplified using Gaussian decomposition of the waveform (Figure 2, left). Representing the waveform as the sum of the Gaussians, smoothes the signal yet allows a means of retaining and identifying the dominant characteristics of the signal for easier interpretation.

Small footprint lidar systems can produce dense sampling of the target surface. The returned signal is also in the form of a waveform, however with discrete return systems, only designated echoes within the waveform are recorded. These can be the first and last returns, or at times, also a number of intermediate points. The amalgamation of these returns from multiple emitted lidar pulses allows the scene to be reconstructed as a 'point cloud' of geolocated intercepted surfaces. This is seen in Figure 2, right, which illustrates the same location as seen within the GLAS waveform. The small footprint lidar point cloud can be interpreted more intuitively as a dominant upper storey of approximately uniform height and a single tree of lower height at the centre of the scene. Points are coloured with respect to their elevation.

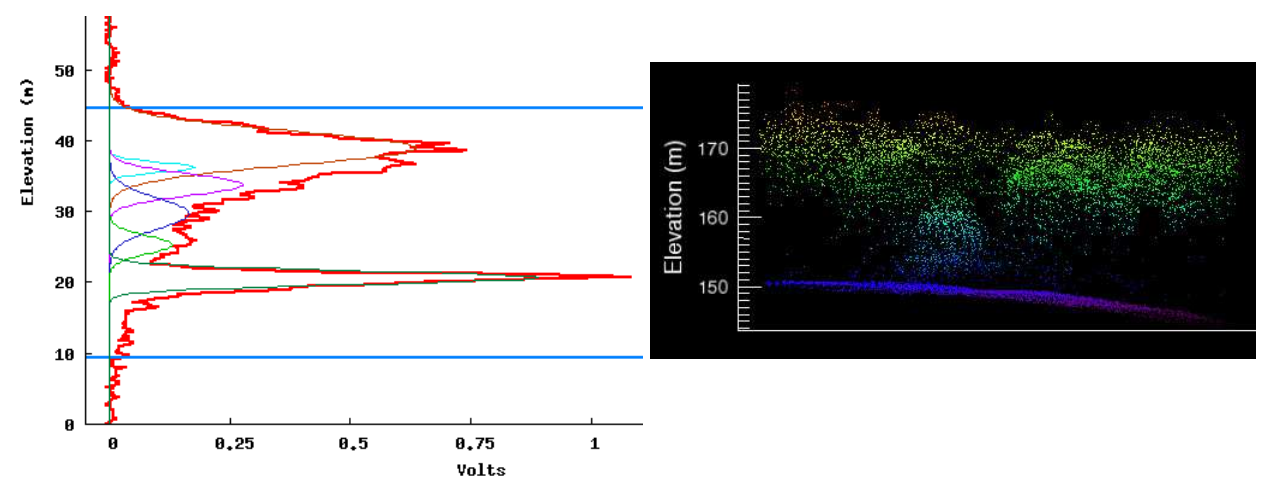

Fig. 2. Example of a waveform produced by a large footprint lidar system (left) and a discrete return lidar point cloud (right) for a coincident area. Location: Forest of Dean, Gloucestershire, UK 


\subsection{Lidar footprint distribution patterns}

Distribution patterns of footprints differ between lidar systems. Lidar profiling involves the systematic location of footprints at intervals along the sensor's path on the ground. These may be contiguous such as the Portable Airborne Laser System of Nelson et al., 2003 (PALS), or placed at discontinuous distances along the ground track in the case of NASA's Geoscience Laser Altimeter System, GLAS (Schutz et al., 2005). This generally permits the sampling of extensive areas, however requires a means to extrapolate biophysical parameter estimates for areas where data were not acquired.

Laser scanning, obtained from an airborne platform, occurs perpendicular to the direction of travel and generally produces a dense distribution of small footprints. Swath width and footprint density are dependent on the altitude and speed of the aircraft plus the scan angle applied. A scanning mirror directs laser pulses back and forth across the flightline causing data to be captured typically in a sawtooth arrangement. The maximum off-nadir scan angle for the instrument can be customised according to the needs of each campaign. Narrower scan angles improve the chances of each shot penetrating dense vegetation canopies and of the sensor receiving a returned pulse from the ground as there is greater likelihood of a clear path through the canopy to the ground. The usual practice is to create an overlap of flightlines similar to photogrammetric surveys of $\sim 60 \%$. Multiple flightlines can then be combined to provide full coverage of the desired area by means of specialised software. Small footprint laser scanning is generally operated at the forest scale, largely due to cost implications.

\subsection{Lidar system configurations}

As discussed above, lidar sensors can be operated at different scales from different altitudes and different viewing perspectives in relation to the target surface; from above in the case of satellite and airborne systems and from below or to the side for terrestrial laser scanners. Lidar instrument specifications therefore vary considerably, combining different sampling patterns on the ground, density and size of individual laser footprints.

Nelson et al's (2008; 2003; 2004) PALS is an example of a small footprint, discrete return, lidar profiler which is operated from an aircraft. Its innovative and portable design has permitted sampling and vegetation parameter estimation at regional scales throughout the world and may be considered a predecessor to the satellite lidar profiling sensor discussed in Section 2.

The Laser Vegetation Imaging Sensor (LVIS) is an experimental lidar instrument developed at NASA Goddard Space Flight Center (GSFC, 2010). It is a full waveform, scanning lidar that emits a $1064 \mathrm{~nm}$ laser beam at a pulse repetition rate of $100-500 \mathrm{~Hz}$. LVIS can operate at an altitude in excess of $10 \mathrm{~km}$ and this offers the capability of producing swaths up to two $\mathrm{km}$ wide and medium-sized footprints of 1-80 m diameter (Blair et al., 1999; Dubayah et al., 2010; GSFC, 2010).

Until relatively recently, small footprint lidar were almost exclusively restricted to discrete return systems within the commercial and operational sector whilst full waveform instruments remained a research and development tool. It should be noted that recent advances in data storage capacity are beginning to open opportunities for small footprint, full waveform scanning systems, however to date, software to process such data is not readily available.

By necessity, this chapter cannot attempt to fully present all combinations of lidar specifications. Readers should note that the multiple vegetation applications of lidar data lead 
to wide-ranging variations in sensor design and characteristics as outlined above. In the descriptions within sections 2-4, an example of a satellite sensor is used to demonstrate the principles of large footprint, full waveform profiling data, whilst airborne and terrestrial lidar instruments are used to provide examples of small footprint, discrete return laser scanning.

\subsection{Key concepts for biomass assessment}

Lidar remote sensing provides a direct estimation of the elevation of intercepted features. In the context of vegetation, if signals from the ground and vegetation can be distinguished, the relative heights above ground of forest canopies can be calculated. Since an adequate stem diameter and canopy structure are needed to support tree dimensions, vegetation height is closely related to volume and therefore biomass. The sections below provide examples of applications of lidar systems for biomass assessment.

\section{Satellite lidar profiling}

NASA's Geoscience Laser Altimeter System (GLAS) aboard the Ice, Cloud and land Elevation Satellite (ICESat) is currently the only satellite lidar system to have provided near global sampling coverage over an extended period of time. It therefore offers a unique dataset of vertical profiles of the Earth's surface.

ICESat was launched in January 2003 and the mission continued until the final laser ceased firing in the Autumn of 2009. During this period, the laser was operated for approximately month-long periods annually during Spring and Autumn, and additionally during the Summer earlier in the mission lifetime.

This is a full waveform, lidar profiling system which operated at an altitude of $600 \mathrm{~km}$, travelling at 26,000 $\mathrm{km} \mathrm{h}^{-1}$ and emitting $1064 \mathrm{~nm}$ laser pulses at $40 \mathrm{~Hz}$. This caused the Earth's surface to be sampled at intervals with footprint centres positioned $172 \mathrm{~m}$ apart. Footprint diameter and eccentricity have varied considerably between laser campaigns from a major axis of $148.6 \pm 9.8 \mathrm{~m}$ to $51.2 \pm 1.7 \mathrm{~m}$ (Figure 3). Comprehensive information regarding the sensor are available from Abshire et al., 2005; Brenner et al., 2003; NSIDC, 2010a; Schutz et al., 2005; Schutz, 2002. Data plus tools to process them are available free of charge from NSIDC, 2010b.

\subsection{Characteristics}

The systematic sampling pattern and representation of the vegetation profile within the returned lidar waveform signal (Figure 2, left) enables the spatial distribution of vegetation parameters to be mapped for large areas. The seasonal coverage allows near repeat measurements at a frequency which would not be feasible using conventional survey methods. However the system was designed primarily for cryospheric applications and therefore the configuration is not considered optimal for vegetation analysis. This poses some challenges for forestry applications. Upon sloped, vegetated terrain, vegetation and ground surfaces may occur at the same elevations. This causes the signals from ground and vegetation to be combined within the waveform and, where it is not possible to distinguish a ground peak, this prevents the signal returned from the vegetation from being reasonably identified. Furthermore, dense cloud cover prevents a valid return signal causing gaps in footprint sampling (Figure 3). For regions with high cloud cover such as the tropics, this can serve to worsen the already-sparse sampling density near the equator, produced by the polar orbit. 


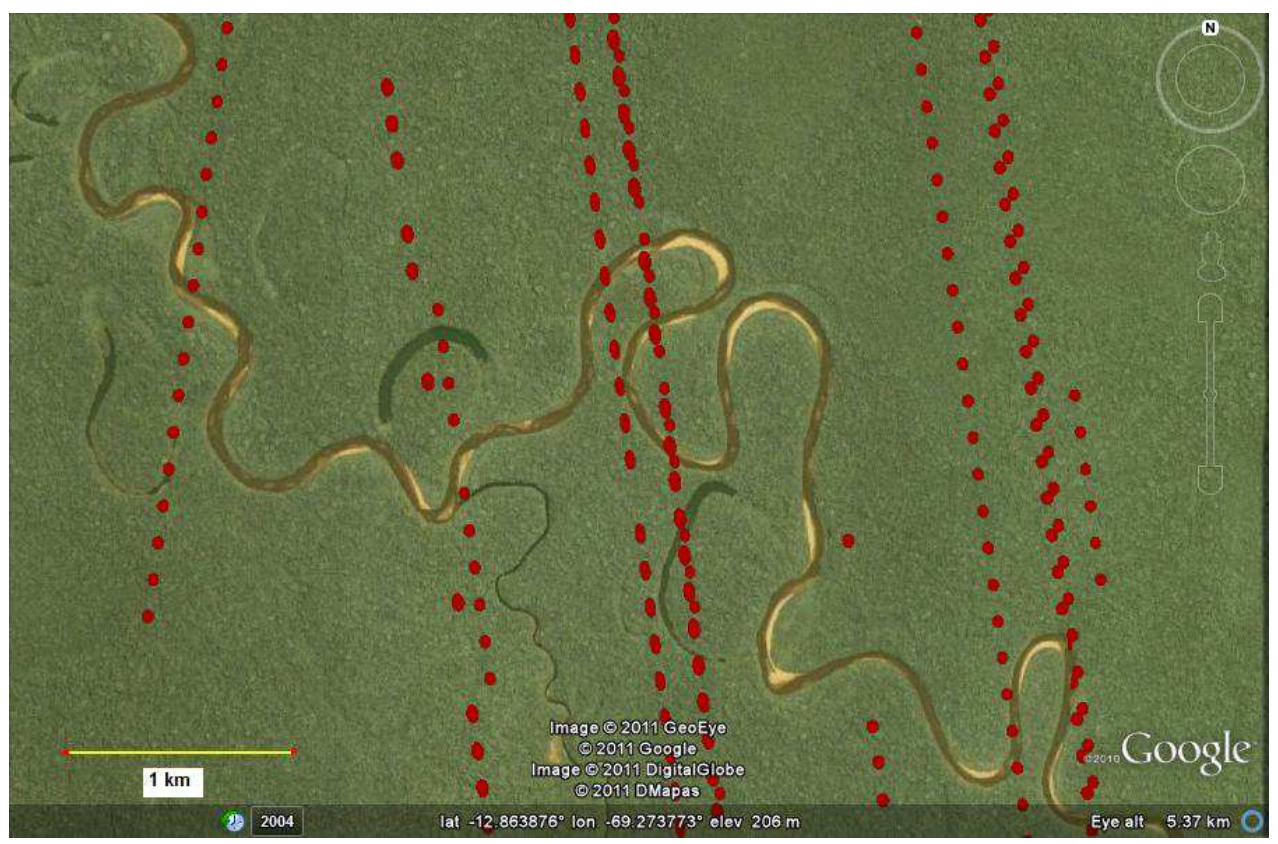

Fig. 3. Multiple GLAS laser campaigns sampling overlaid on a GoogleEarth image of Tambopata, Peru. Missing data are found where dense cloud prevents sufficient energy from penetrating to the Earth's surface and returning to the sensor.

Within each footprint, if the top of the canopy is assumed to be the start of the waveform signal (upper horizontal blue line, figure 2 left), the accuracy with which the signal returned from the vegetation can be identified depends on the ability to identify a representative ground surface within the waveform. Methods to achieve this have included the use of an independent DTM to account for terrain slope within lidar footprints (Lefsky et al., 2005; Rosette et al., 2008) or using Gaussian decomposition of the waveform to locate a peak corresponding to the ground surface (Rosette et al., 2008; Sun et al., 2008a; Sun et al., 2008b). Vegetation height can therefore be estimated as the elevation difference between the start of the waveform signal and the identified ground surface estimated within the waveform. The studies above report RMSE as 3+ metres.

\subsection{Applications for biomass estimation}

Most commonly, waveform indices of Height of Median Energy (HOME) or relative height percentiles above ground $\left(R H_{i}\right)$ are calculated using the cumulative energy distribution within this region of the waveform returned from vegetation. More recently, Lefsky et al., 2007, devised an alternative method of estimating a vegetation height parameter which accounts for terrain and vegetation roughness using the waveform leading and trailing edges rather than isolating the signal returned from vegetation.

The sampling measurements produced within the satellite lidar footprints are typically combined with coincident field measurements of biomass. This enables regression equations to be developed using waveform metrics to estimate biomass for the areas 
sampled by the lidar footprints. The continuous spatial coverage of optical or radar data permit these estimates to be extrapolated.

Similar data fusion techniques have been used to determine biomass distribution by several authors and encompass a wide breadth of vegetation types and have been applied from regional to continental scales, including a focus on Africa's mangrove forest (Fatoyinbo \& Simard, in press 2011), Siberia (Nelson et al., 2009), Quebec (Boudreau et al., 2008), and for mapping throughout Africa (Baccini et al., 2008). Work is currently underway by the latter research group at Woods Hole Research Center, led by Josef Kellndorfer, to estimate tropical forest biomass globally (WHRC, 2011). Additionally, research utilising GLAS is in progress as part of NASA's Carbon Monitoring System initiative (NASA, 2010) to determine biomass distribution within the US (as well as to produce higher resolution biomass maps at a county level using airborne lidar data).

Global vegetation height products derived from GLAS and optical data (Lefsky, 2010; Los et al. 2011) or combining GLAS and radar data (Simard, 2011) open possibilities to improve our understanding of global processes (Los et al., 2008) as well as allowing applications for biomass assessment.

However, comparability of data and methods must be taken into consideration. These methods rely on the application of regression equations to extend vegetation parameter estimates across large areas. Nelson, 2010 demonstrates how the calculation of biomass is often sensitive to the equation applied and lidar sensor characteristics. These inconsistencies have implications for repeat analysis and monitoring of change due to the effect of model selection and lidar system evolution on the outcome of biomass assessment.

\section{Airborne lidar systems}

\subsection{Characteristics}

The use of airborne laser scanning data in forest applications has attracted increasing interest over the last decade. Nowadays, lidar is perceived to provide a cost-effective and precise assessment of the vertical and horizontal structure of woodland areas and, therefore, a valid alternative or complementary approach to current field methods for inventory (Wulder et al., 2008). Vertical location of points are often reported to 1ns $(\sim 15 \mathrm{~cm})$ precision whilst horizontal gelocation accuracy may be expected in the region of $20-30 \mathrm{~cm}$.

In this section, an overview is given of small footprint airborne laser scanning applications for both stand-level assessment and the estimation of vegetation parameters at an individual tree level. For a comprehensive description of the use of airborne lidar for forestry purposes including forest community structure, growth assessment, tree stability and timber quality, please refer to Suárez, 2010.

Airborne lidar systems provide relatively dense sampling coverage with footprint size in the region of tens of centimetres. However, they are commonly reported to underestimate canopy height as a result of point distribution and density. This is due to some degree of canopy penetration of the signal that varies according to species (Næsset, 2004). In general, this underestimation is less pronounced for cone-shaped trees like spruce or Douglas fir (Pseudotsuga menziesi) than for spherical-shaped trees like many broadleaves or even Scots pine (Pinus sylvestris L.). Conifers normally create more compact shapes with less energy penetration through the canopy than broadleaves. So, energy returns tend to be produced 
from the outer layers of the canopy. However, the degree of penetration is ultimately related to a combination of factors such as the sampling density, beam divergence and scanning angle (Suárez et al., 2005).

Possible scenarios may be as illustrated in Figure 4 below. With higher density of laser pulses, these difficulties are reduced but at the cost of higher operating expense and flight duration restrictions limiting spatial coverage.

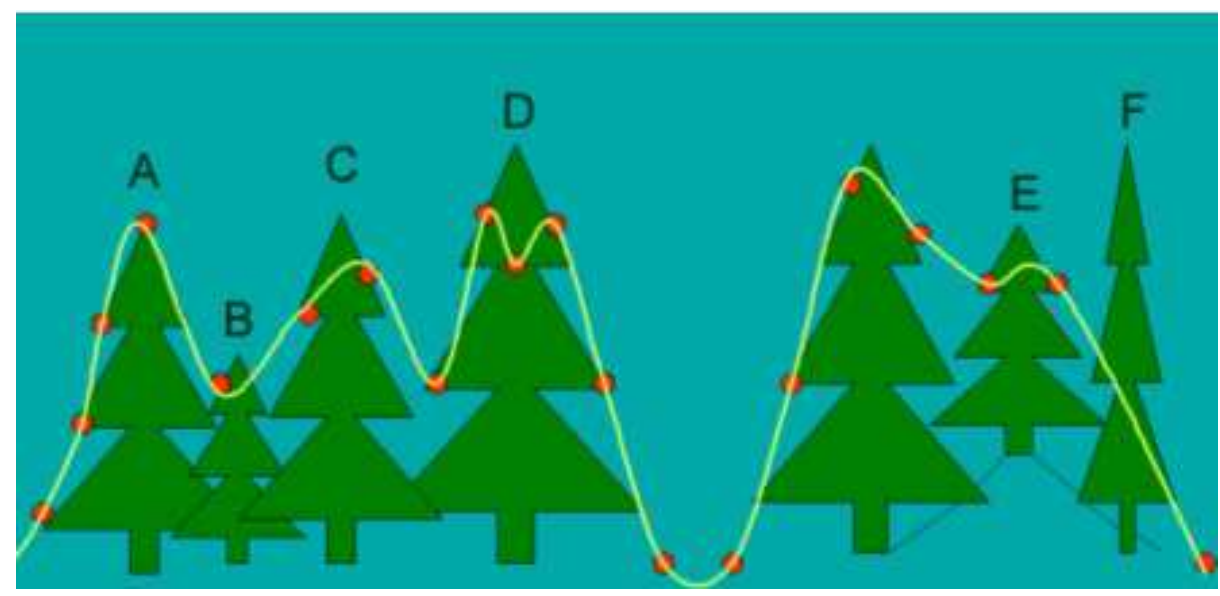

Fig. 4. Possible scenarios of lidar point cloud interception of the forest canopy. Source: Suárez et al., 2005.

a. Laser hits the true top of the canopy,

b. Small trees close to larger neighbours are ignored,

c. The most likely situation: laser returns do not hit the true top of the tree,

d. One of the pulses is intercepted at a lower height due to canopy penetration wrongly suggesting two tree tops,

e. Trees on a mound can be assigned a greater height in the absence of a good model of the ground surface beneath,

f. In a situation of sparse density of returns some trees can be ignored completely

Despite common perception, lidar does not create tomographic images and, therefore, they cannot be considered as 3-D representations in the strict sense. Only the gaps in canopy cover and transmittance through leaves will allow laser energy to be returned from the ground. As with full waveform data, the critical step for the calculation of vegetation height metrics is to distinguish between those points returned from ground and non-ground surfaces.

Since lidar energy penetration through the vegetation canopy will vary with forest structure, density and laser scanning angle in particular, the last return of an emitted lidar pulse may not necessarily be returned from the ground surface. Therefore a means of filtering points is necessary in order to differentiate those returns reaching the ground from those being intercepted at different heights within the canopy (e.g. Kraus \& Pfeiffer, 1998; Zhang et al., 2003). A thorough comparison of different approaches and a complete description of filters can be found in Sithole \& Vosselman, 2004. This allows the classification of points into ground and vegetation classes (Figure 5). Other algorithms can refine the classification further to additionally identify features such as buildings, electricity cables, etc. 
The use of airborne lidar data in forestry was originally focused on the construction of two cartographic products: Digital Terrain Models (DTMs) and Digital Surface Models (DSMs), which are used to describe the underlying terrain and top of forest surfaces respectively. These products are used to generate canopy height models (CHM) that subsequently provide accurate estimates of important forest parameters such as canopy heights, stand volume, and the vertical structure of the forest canopy. The estimation of canopy heights is performed by the subtraction of bare ground values (DTM) from the canopy layer (DSM). An accurate estimation of a CHM relies heavily on a good approximation of the ground surface underneath.

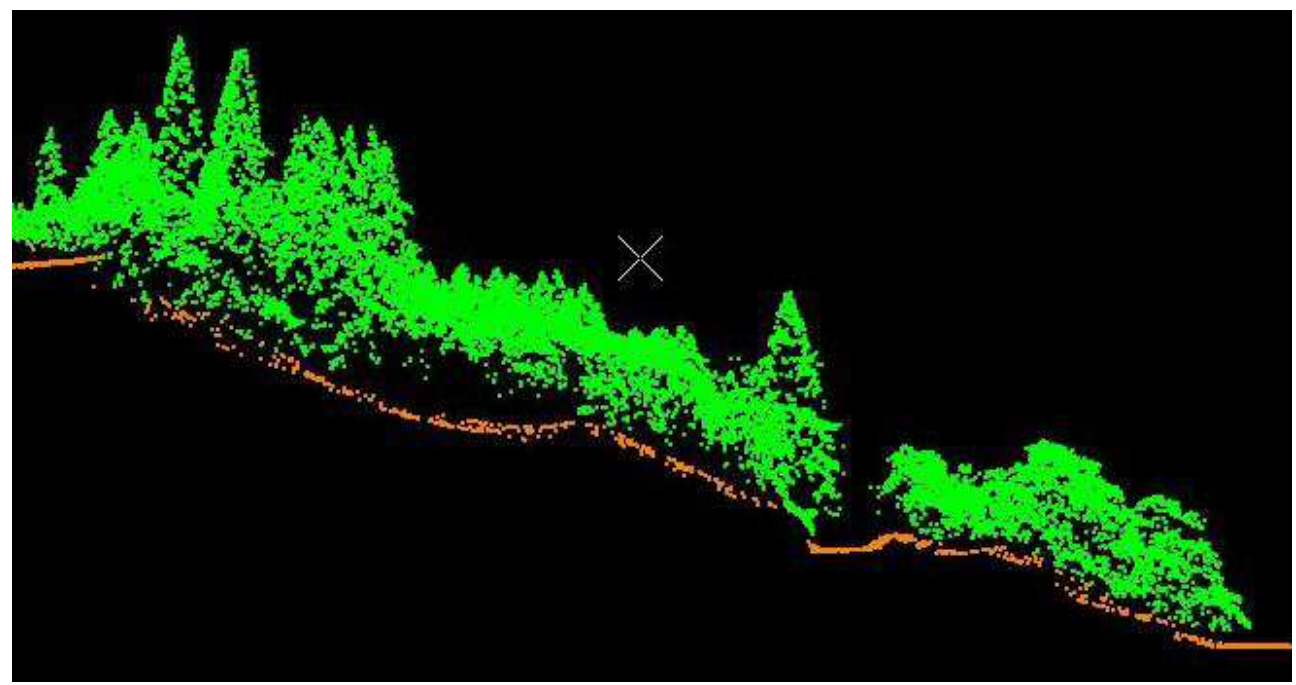

Fig. 5. Vegetation distribution and structure shown by classification of an airborne lidar point cloud. Data illustrated were provided courtesy of Forest Research, UK. Location: Scottish Highlands, UK.

More recently, increasingly sophisticated means of analysis are being applied for the estimation of important parameters at both stand (number of trees, volume, basal area, top height, percentage of canopy cover and crown layers) and individual tree level (individual tree heights, stem diameters and crown metrics). The potential areas of application span from timber production to biological diversity, carbon sequestration or general environmental protection. Section 3.2 below considers both approaches.

\subsection{Applications for biomass estimation}

\subsubsection{Stand level analysis}

Stand-level inventory from airborne lidar follows a method originally devised by Næsset, 1997a, b. These two studies are particularly relevant because both have encouraged further work based on the notion that lidar data can be used in large-scale forest inventories, provided that georeferenced data from field plots could be used in a first phase to develop empirical relationships between lidar metrics such as percentiles of relative height above ground and the main parameters for forest management. Such relationships are used to 
estimate, in a second phase, forest stand parameters for all the test plots in the study area, known as two-stage procedure for stand inventory (Næsset, 2002).

In this way, the stand-level approach provides a useful estimation of key stand parameters such as top height, canopy cover, tree density, basal area and volume. The established relationships allow forest parameters such as biomass to be directly inferred from the use of lidar metrics and for this assessment to be implemented across large forest areas where there is lidar coverage. Lidar systems provide point-wise anisotropic sampling unlike the full area coverage common in optical systems. As a result, laser data are interpolated in order to convert the same coverage to a continuous surface working-image and allow the distribution of forest parameters to be mapped.

This method does of course have some limitations. It is heavily dependent on abundant field data collection to train empirical relationships between field and lidar data that often are not easily transferable to other study areas. Different relationships may be present for morphologically similar species (Norway spruce, Sitka spruce or larch) and additionally, stand structure is a significant determinant factor. The effects derived from the spatial distribution of gaps, their size and the spatial distribution of standing trees (whether perfectly aligned, growing in a natural stand or thinned at different intensities) on the vertical interception of laser hits are not parameterised in this approach.

However, the real value of this method is demonstrated in its application in regional studies, where the combination of lidar and field measurements can optimise traditional surveys, particularly as part of large area forest inventories (Hollaus et al., 2009).

\subsubsection{Individual tree based inventories}

Variability in characteristics is a feature of natural systems. Even in systems designed to be as uniform as possible, such as planted forests in monocultures, growing differences are inevitable. Understanding the factors controlling variability is important in developing our knowledge of how ecosystems operate and behave such as the way that trees grow and accumulate biomass in response to their environment and close interaction with their neighbours (e.g. competition for space, light and nutrients). Identifying and locating trees using airborne lidar data permits the spatial variability of biomass distribution within a forest to be considered.

Canopy delineation algorithms have been developed by several authors and most of these detect single trees using an interpolated canopy height model (section 3.1) by the detection of local maxima for tree location and watershed or pouring algorithms (as well as derivations of these algorithms) for the delineation of single tree crowns (e.g. Popescu et al., 2003). However, latterly, approaches are becoming increasingly based on raw data using clustering or blob detection methods (e.g. Morsdorf et al., 2004).

Figure 6 illustrates the delineation of individual tree crowns shown outlined by blue polygons and overlaid on a lidar canopy height model. Lighter grey shades indicate taller heights which are used to identify tree tops to infer height of individual trees.

Using known allometric relationships between tree height and crown width (derived from crown area) with stem diameter at breast height, volume can be calculated on an individual tree basis by approximating tree stems as a cone or by using more sophisticated taper functions or a crop form parameter which defines mean taper characteristics in a stand (Edwards \& Christie, 1981; Matthews \& Mackie, 2006). Individual tree volume can then be converted to biomass (by accounting for specific density) allowing the spatial distribution and variability of biomass to be mapped. 


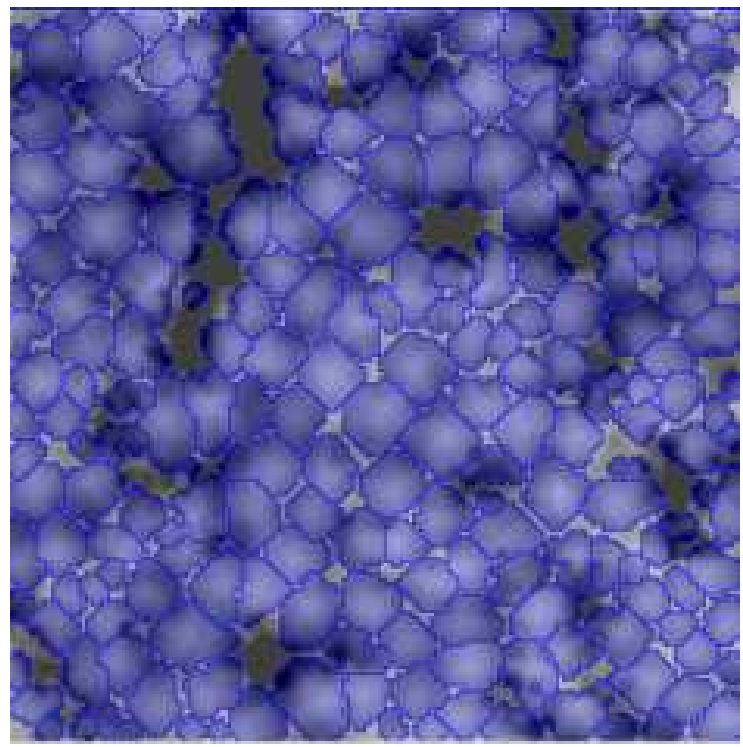

Fig. 6. An example of tree crown delineation with airborne lidar data using object oriented analysis in Definiens Developer (Source: Suárez, 2010).

Results show that lidar can detect most of the crowns of dominant and co-dominant trees in mature stands dominated by coniferous species, but finds difficulties for suppressed or subdominant trees, young stands, groups of trees growing in close proximity and for deciduous species. This will have an effect on biomass estimation when aggregating individual tree estimates to a stand level.

Small individuals will contribute relatively less to the overall stand volume than larger trees. However in many situations they may form a significant contribution to total biomass which should be accounted for. Authors such Maltamo et al., 2004 have shown it to be possible to predict the height of small trees not detected by lidar using Weibull distributions.

The detection and estimation of individual tree heights for deciduous species is more difficult because of their more spherical crown shape compared to conifers (meaning that the tree top and crown boundaries can be located with less certainty using a $\mathrm{CHM}$ ) and the higher probability for the occurrence of more than one apex in each tree. Moreover, crown delineation in deciduous stands becomes more difficult because the crowns of neighbouring trees often overlap (this is a common situation in conifer stands too).

The single tree approach allows individual tree counts, crown volume calculations, canopy closure or single tree height estimates. These are important inputs in order to derive estimates of diameter at breast height (DBH) distributions, volume or biomass. Published studies show that good results can be achieved with $65 \%$ to $90 \%$ of correct tree counts within conifer stands while for broadleaf trees the results are less accurate and an underestimation of volume is often reported.

Using canopy delineation from airborne lidar data, parameters such as biomass can be determined and spatially located in relation to their surroundings. This also allows the inhibiting effects on biomass accumulation introduced by larger trees over more disadvantaged neighbours to be observed. 


\subsection{Summary}

In operational terms, current usage of airborne lidar data is generally confined to statistical analysis at stand/forest scales (Næsset, 1997a, b). Although the method has undergone minor adaptations by several authors, this approach has become a standard practice for large-scale inventories in some European countries (Finnish_Forest_Association, 2007; Hollaus et al., 2009; Næsset, 2004).

Airborne lidar point clouds can be understood and interpreted intuitively and vegetation can be placed in the context of terrain, access routes and neighbouring competitors. The ability to remove the vegetated surface to reveal the terrain beneath provides valuable information for management purposes and topographic assessment.

Regression equations for biomass estimation may be site specific, however good relationships have been demonstrated using broad class distinctions such as broadleaves, conifers and mixed stands which may be more readily available using optical data or land cover type maps. This enables the spatial distribution of biophysical parameters to be represented over a forest scale which would be impossible using traditional field measurements.

The cost of airborne coverage may prohibit repeat lidar campaigns and so at best, such detailed information is likely to be available infrequently to monitor growth. However, looking to the future, several European countries have undertaken campaigns for partial or complete nation-wide coverage of airborne lidar data including The Netherlands (Duong et al., 2009), Norway, Austria, Switzerland (Swisstopo, 2011) and Finland (Finnish_Forest_Association, 2007). A similar commitment of lidar acquisition is in progress in Spain on a region-by-region basis where the value-added benefit of such a resource has been recognised for economic and social invigoration (Dielmo, 2011).

Whilst generally of mid-low point density by necessity of cost and not necessarily intended specifically for vegetation applications, nevertheless, such previously-unobtainable national vertical profile datasets offer potential applications for a multitude of applications including mapping and reducing uncertainty of biomass distribution. Furthermore, as outlined above, airborne lidar data are already playing a significant role in large-scale forest inventory efforts.

\section{Terrestrial laser scanning}

\subsection{Characteristics}

The small and portable terrestrial lidar systems can be mounted on a static tripod or transported on a moving vehicle and therefore can be easily taken into the field. GPS measurements also allow these scans to be geolocated. In contrast to the viewing perspective from above provided by satellite and airborne sensors, terrestrial lidar provides a clear view of the tree stem, understorey and ground surface (Figure 7).

This measurement of a relatively small area within viewing distance of the scanner can be considered to replicate field plot measurements, however additionally provides an understanding of context which would not be possible from field data. The upward looking approach often leads to difficulty in detecting tree tops, however representation of tree stems, ground surface roughness and understorey vegetation offer a level of detail which cannot be retrieved using airborne instruments.

This approach causes only the side of stems facing the scanner to be detected in any one scan and also obscures the view of trees which are behind those closer to the instrument. Therefore 
the combination of several scans is often required to accumulate adequate information for analysis of the scene within a plot. Low vegetation and heavy branching can affect the quality of the data and in some studies were removed before the site was scanned. This difficulty is especially important with the trees closest to the scanner as they cause the most occlusion.

Research into the detection and reconstruction of stems (e.g. Huang et al., 2011) and branches (e.g. Bucksch \& Fleck, 2011) is a current area of development which is of great interest. For forestry purposes this would permit the quality of timber to be determined more easily, such as stem straightness, branch number and branch angle. The ability to reconstruct the tree geometry from terrestrial laser scanning is unprecedented. Whilst for the purposes of forest inventory, the ability to detect the ground surface, height above the ground along the tree stem and to determine the size of the stem allows diameter at breast height to be directly measured, which is one of the most fundamental operational parameters collected by foresters in the field.

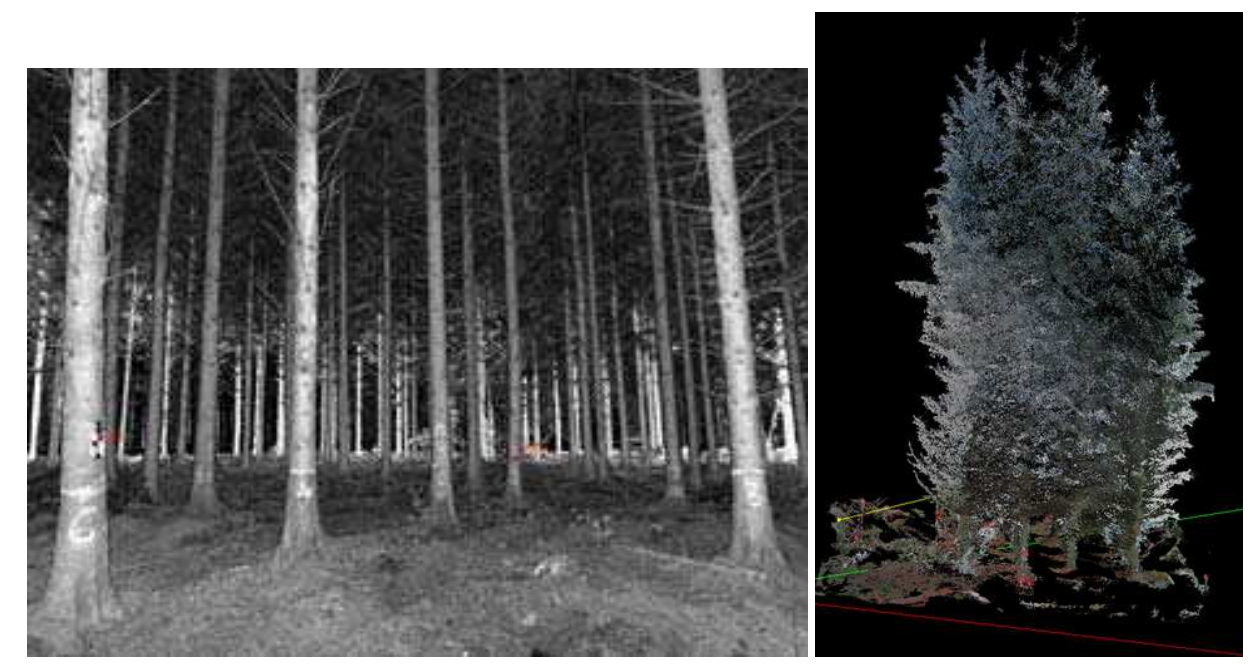

Fig. 7. Below-canopy plot sampling using terrestrial laser scanning. Images courtesy of Forest Research, UK.

\subsection{Applications for biomass estimation}

Terrestrial laser scanning has been applied within the commercial forestry sector. An example of which is TreeMetrics Ltd., Cork, Ireland, who have adapted this technology and developed purpose built software called AutoStem Forest ${ }^{\mathrm{TM}}$ to process laser scans into forest inventory-specific data. The principle behind this methodology is to extract greater value from the resource.

The application is intended principally to complement existing inventory methods by creating and measuring individual tree volumes, their straightness and calculating their potential end products. The technology may be considered as a virtual timber harvesting machine that gathers precise data as it scans trees. By positioning laser scan plots throughout a forest, it is possible to measure the variability within the forest and to describe the forest as a Timber Warehouse ${ }^{\mathrm{TM}}$ for commercial purposes or to map biomass distribution for inventory applications. 
Aside from forestry management objectives, the use of terrestrial lidar can potentially complement traditional field data collection by improving the efficiency and accuracy of survey approaches. Whereas the time required to measure the trees within an inventory plot by a team of surveyors may be quite considerable, the combination of lidar scans of a few minutes each could substantially reduce this whilst providing additional contextual information which could not be achieved with field measurements.

Terrestrial laser scanning measurements are restricted to small area sampling, similar to typical field data collection. However, this permits the plot to be 'revisited' visually and analytically for multiple purposes without returning to the field, allowing the scene to be reconstructed to enable trees to be placed in the context of their immediate surroundings. For management purposes, this could be invaluable to determine optimum thinning or harvesting times or to assess growth trends against model predictions through the measurement of diameter increments.

Once diameter distributions within measured plots are calculated, in the same way as with field approaches, allometric relationships allow wider stand-level forest attributes to be inferred. If applicable species groupings are known, general DBH-based regression equations can be applied to estimate forest stand-level biomass. For sites within the USA, Jenkins et al., 2003, 2004 present diameter-driven allometric equations for biomass of North American species whilst for Europe, a similar resource is provided by Zianis et al., 2005.

\section{Further applications of lidar remote sensing}

\subsection{Forest growth models}

Forest growth models such as the Ecosystem Dynamics model, ED, (Hurtt et al., 2004) and the Tree and Stand Simulator, TASS, (Goudie \& Stearns-Smith, 2007) enable forest growth scenarios to be predicted. Remote sensing analysis can be used as a valuable tool to provide observational inputs to models and in order to produce detailed inventories for long-term scenario modelling.

Airborne lidar stand level analysis can be used to produce statistically-derived model inputs. This approach is being undertaken as part of the NASA Carbon Monitoring System (NASA, 2010) using an interpolated surface $80^{\text {th }}$ percentile canopy height model as an input to the ED model (e.g. Hurtt et al., 2004). This method can potentially be applied across large areas and could be achieved with relatively low density lidar data such as might be acquired for regional or national campaigns.

Alternatively, Suárez, 2010, used a tree list generated from individual tree delineation as baseline inventory data from which to predict future scenarios and demonstrate processes at work within stands using the distance-dependent model TASS. These processes include competition, establishment of a dominance hierarchy and recovery from catastrophic events such as wind damage or thinning. This means that the biological principles behind such models adapt them to local conditions, unlike empirical models and suggesting wider application may be possible.

The temporal dimension provided by the TASS simulations provides a valuable insight into the long-term effects of each stand intervention or natural disturbance. Not only growth increments, but timber products can also be predicted with this method. In addition, management practices can be balanced by the constraints introduced by the future risk of wind damage. The scale of analysis and the possibility of creating future scenarios contribute to a substantial reduction in the level of uncertainty associated with forest management. 
Lidar data therefore provide a useful contribution as a baseline input position from which future scenarios can be determined. Subsequent lidar campaigns or observations of landcover disturbance from optical data (Huang et al., 2010) could furthermore allow model predictions to be validated or calibrated to closer match observed growth trends.

\subsection{Prospects for global modelling}

Vegetation plays a significant role in global climate, water, energy and biogeochemical cycles, particularly concerning carbon, with approximately one quarter of atmospheric carbon dioxide fixed annually as gross primary production. To accurately model this and other land surface processes in General Circulation Models (GCM), properties such as radiation absorption, plant physiology, surface characteristics and climatology are required. These models require multitemporal global datasets that can only be obtained from remotely sensed sources.

Computer-generated models of the biosphere provide a valuable means to improve understanding of the immensely complex interactions between interdependent systems affecting the Earth. By their very nature, models function as generalisations of reality and a series of component models replicating the interplay of systems often provide input to complex broader-themed Biosphere models.

Dynamic Vegetation Models are particularly valuable in enabling prediction of the carbon balance under changing ecosystem structure and composition brought about by climatic changes. Vegetation is often represented within each grid cell as generalised Plant Functional Types and climate-driven habitat changes are used to model vegetation succession and plant lifecycle. Where vegetation height is currently considered as static over time, models could benefit from future global lidar observations of vegetation height (e.g. Lefsky, 2010, Los et al., 2011) or biomass, particularly if signal sensitivity permits growth over the sensor lifetime to be observed. Furthermore, the use of lidar could inform validation of LAI, fractional canopy cover or NDVI products (Los et al., 2008, 2011) which are produced using indirect relationships with optical reflectance properties.

\section{Emerging technologies}

\subsection{Waveform simulation and multispectral lidar}

Previous work has demonstrated the value of lidar modelling of vegetation for discrete return lidar (Disney et al., 2010) and full waveform systems (Ni-Meister et al., 2001; North et al., 2010; Sun \& Ranson, 2000). Using a simulation approach, the sensitivity of lidar data to surface structural and optical properties can be explored to improve our understanding and interpretation of the estimation of lidar-derived biophysical parameters.

Recent discussions have turned to the prospects of multispectral lidar sensors for vegetation analysis (cArbomap, 2011; Woodhouse et al., in press 2011). This project is led by Dr Iain Woodhouse at the University of Edinburgh and the concept has been considered in a simulation study by Morsdorf et al., 2009. The authors demonstrated the opportunity of detecting seasonal and vertical change in normalised difference vegetation index (NDVI) which would allow canopy and ground signals to be distinguished. The variability of chlorophyll content during the growing season was also detected thereby indicating the amount of photosynthetically active biomass.

Additionally, Hancock, 2010 has demonstrated the potential offered by dual wavelength lidar using wavelengths selected either side of the electromagnetic spectrum red edge. A 
reflectance ratio is calculated and this profile allows the signals within the waveform from ground and vegetation to be differentiated. This would offer a valuable response to the challenging situation of combined vegetation and ground signals within large footprint waveforms on sloped surfaces.

Once issues of eye sensitivity at optical wavelengths and energy requirements are fully addressed, multispectral lidar concepts could offer the opportunity for enhanced vegetation analysis using lidar systems.

\subsection{Photon counting lidar systems}

The emerging technology of photon counting lidar offers the potential for low energy expenditure and potential high altitude operation allowing extended laser lifetime and large area coverage. This newest type of lidar technology is currently generally operated at green wavelengths $(532 \mathrm{~nm})$, in some airborne systems due to a greater efficiency of the detector and, in the case of NASA's ICESat II, as a result of technical readiness. Low laser energy output ensures eye safety of these instruments despite operating at a visible wavelength. A high pulse repetition rate and photon detection probability produces a high point density even whilst flying at greater altitudes whilst a narrow pulse duration ( $1 \mathrm{~ns})$ allows photons to be located with greater vertical precision.

One significant factor is that photons returned from the emitted pulse cannot be distinguished from ambient noise. Acquiring data at night or dusk would minimise the difficulties of noise posed by solar background illumination, and sensor specifications such as the use of a small detector instantaneous field of view would also assist this.

Initial analysis within NASA's Carbon Monitoring System initiative (NASA, 2010) using the 3D Mapper single photon scanning lidar developed by Sigma Space Corporation, USA, suggests that promising results may be obtained from small footprint photon counting sensors for the generation of vegetation products. The greater point density of the point cloud which is produced, in excess of that which is typically collected by discrete return airborne lidar data, aims to improve the characterisation of vegetation canopies and offers the opportunity for established analysis techniques to be applied to this new technology.

The Slope Imagining Multi-polarisation Photon-counting Lidar (SIMPL) is an example of an airborne small footprint photon-counting profiling lidar which operates at both $1064 \mathrm{~nm}$ and $532 \mathrm{~nm}$ wavelengths (Dabney et al., 2010). A single pulse is emitted which is split into four beams, each with four channels for green and NIR wavelengths, each of which at parallel and perpendicular polarisations. The two polarisations respectively identify photons which have been reflected from a single surface or which have undergone multiple scattering. The four beams are distanced approximately 5 metres apart, producing four profile 'slices' through the canopy. The laser repetition rate of $11.4 \mathrm{kHz}$ and an aircraft speed of $100 \mathrm{~m} /$ second may be expected to produce 5-15 detected pulses per square metre.

Using SIMPL, Harding et al., in press 2011, have explored the influence of lidar wavelength on the ability to determine standard waveform metrics which may be employed to predict biomass. By aggregating detected photons over a distance along the transect, the authors calculated a cumulative height distribution (such as that used for waveform or discrete return analysis). Height of median energy (HOME) and canopy cover metrics were compared and little difference was found between the two wavelengths, suggesting that lidars using 532nm could produce comparable biomass estimates to those obtained by current $1064 \mathrm{~nm}$ systems. 
NASA's forthcoming ICESat II mission is due for launch in early 2016 (GSFC, 2011). In contrast to ICESat I, its successor will carry a medium footprint, photon-counting profiling lidar operating at $532 \mathrm{~nm}$ wavelength. This instrument is named ATLAS, the Advanced Topographic Laser Altimeter System. The current planned configuration is for a single emitted pulse which is split into six beams, arranged as three adjacent pairs. Each pair will have a stronger and a weaker beam $(100 \mu \mathrm{J}$ and $25 \mu \mathrm{J}$ respectively) which aims to address issues of detector sensitivity when alternating between bright and dark surfaces such as ice and water. A distance of $3.3 \mathrm{~km}$ is anticipated between each pair and members of the pair will be separated by $90 \mathrm{~m}$. The high repetition rate of $10 \mathrm{kHz}$ from an altitude of $\sim 496 \mathrm{~km}$ will produce overlapping footprints of $10 \mathrm{~m}$ diameter which will be distanced at $0.7 \mathrm{~m}$ intervals. 1-3 photons are anticipated to be detected per footprint and, although the spatial location of photons within the footprint will be unknown, the aggregation of returns along the ground tracks will allow a vertical profile to be created. Although, like with its predecessor, the primary objective of ICESat II is not the retrieval of vegetation, one of its science objectives is measuring vegetation height as a basis for estimating large-scale biomass and biomass change (GSFC, 2011). This new technology will offer a new perspective of the world and open opportunities for different approaches to global vegetation analysis.

\section{Discussion and conclusion}

Laser altimetry is currently the only technique capable of measuring tree heights in closed canopies and therefore offers a remote and non-destructive means of estimating vegetation volume, biomass or carbon content to account for vegetation distribution. This avoids difficulties posed by inaccessibility, time or cost-intensive field campaigns.

The replacement of current field-based methods is not contemplated as a realistic option, however, data collection in the field can be made more effective and targeted as a result of lidarbased inventories. This is already happening in Norway for example, where $90 \%$ of stand inventories are being made in relation to lidar surveys (E. Næsset, personal communication).

At present, the retrieval of stand and individual tree parameters is highly dependent on field data collection for the calibration and validation of a sensor's estimates. However, the most efficient use of lidar will require a deeper understanding of the phenomenology of tree interception of the laser hits and how this relates to the physical characteristics of the vegetation being monitored. This understanding can be improved using lidar simulation models. This may offer the possibility to construct more widely applicable height and diameter recovery models using current allometric relationships derived from models or by observations from a network of nationwide permanent sample plots.

The recognition of the importance of biomass mapping and the significant contribution of lidar data for this purpose are demonstrated by the investment and commitment by the US Congress to research in this field at both county and national scales through the NASA-led Carbon Monitoring System initiative (NASA, 2010). This project integrates the use of multiple datasets to generate national and county level biomass products. Elsewhere, the investment in airborne lidar by several governments for national scale campaigns further demonstrates the important role that this technology can play in forest inventory and monitoring.

Such means of identifying areas of forest biomass change can offer important contributions to efforts to inform and encourage practices of Reducing Emissions from Deforestation and forest Degradation in developing countries - REDD (Asner et al., 2010; FAO et al., 2008) and to report on Land Use, Land Use Change and Forestry - LULUCF (IPCC, 2003). 
As emerging technologies such as photon counting or multispectral lidar sensors come into operation, the capacity for wider coverage and increasingly accurate lidar-derived applications for biomass assessment will further expand.

\section{References}

Abshire, J., Sun, X., Riris, H., Sirota, J., McGarry, J., Palm, S., Yi, D. and Liiva, P. (2005). Geoscience Laser Altimeter System (GLAS) on the ICESat Mission: On-orbit measurement performance., Geophysical Research Letters, 32: L21S02.

Asner, G., Powell, G., Mascaro, J., Knapp, D., Clark, J., Jacobson, J., Kennedy-Bowdoin, T., Balaji, A., Paez-Acosta, G., Victoria, E., Secada, L. and Valqui, M. (2010). Highresolution forest carbon stocks and emissions in the Amazon, PNAS, 107(38): 1673816742.

Baccini, A., Laporte, N.T., Goetz, S.J., Sun, M. and Dong, H. (2008). A first map of tropical Africa's above-ground biomass derived from satellite imagery, Environmental Research Letters, DOI: 10.1088/1748-9326/3/4/045011.

Baltsavias, E.P. (1999). Airborne Laser Scanning - Basic Relations and Formulas, ISPRS Journal of Photogrammetry and Remote Sensing, 54: 199-214.

Blair, J.B., Rabine, D.L. and Hofton, M.A. (1999). The Laser Vegetation Imaging Sensor: a medium-altitude, digitisation-only, airborne laser altimeter for mapping vegetation and topography, ISPRS Journal of Photogrammetry and Remote Sensing, 54: 115-122.

Boudreau, J., Nelson, R., Margolis, H., Beaudoin, A., Guindon, L. and Kimes, D. (2008). Regional aboveground biomass using airborne and spaceborne LiDAR in Québec, Remote Sensing of Environment, 112: 3876-3890.

Brenner, A., Zwally, H., Bentley, C., Csatho', B., Harding, D., Hofton, M., Minster, J.-B., Roberts, L., Saba, J., Thomas, R. and Yi, D. (2003). Derivation of Range and Range Distributions from Laser Pulse Waveform Analysis for Surface Elevations, Roughness, Slope and Vegetation Heights; Algorithm Theoretical Basis Document Version 4.1. NASA Goddard Space Flight Center.

Bucksch, A. and Fleck, S. (2011). Automated Detection of Branch Dimensions in Woody Skeletons of Fruit Tree Canopies, Photogrammetric Engineering and Remote Sensing, 77(3): 229-240.

cArbomap (2011). cArbomap; Multispectral lidar. Available online at: carbomap.com.

Dabney, P., Harding, D., Abshire, J., Huss, T., Jodor, G., Machan, R., Marzouk, J., Rush, K., Seas, A., Shuman, C., Sun, X., Valett, S., Vasilyev, A., Yu, A. and Zheng, Y. (2010). The Slope Imaging Multi-polarization Photon-counting Lidar: development and performance results, IEEE International Geoscience and Remote Sensing Symposium, 11686732, DOI 10.1109/IGARSS.2010.5650862, pp. 253-256.

Dielmo (2011). Online data server for airborne lidar. Available online at: www.dielmo.com.

Disney, M.I., Kalogirou, V., Lewis, P., Prieto-Blanco, A., Hancock, S. and Pfeifer, M. (2010). Simulating the impact of discrete-return lidar system and survey characteristics 
over young conifer and broadleaf forests, Remote Sensing of Environment, 114: 15461560.

Dubayah, R.O., Sheldon, S.L., Clark, D.B., Hofton, M.A., Blair, J.B., Hurtt, G.C. and Chazdon, R.L. (2010). Estimation of tropical forest height and biomass dynamics using lidar remote sensing at La Selva, Costa Rica, Journal of Geophysical Research, 115.

Duong, H., Lindenbergh, R. and Vosselman, G. (2009). ICESat Full-Waveform Altimetry Compared to Airborne Laser Scanning Altimetry Over The Netherlands, IEEE Transactions on Geoscience and Remote Sensing, 47(10): 3365-3378.

Edwards, P.N. and Christie, J.M. (1981). Yield Models for Forest Management; Booklet 48. The Forestry Commission, Edinburgh.

FAO, UNDP and UNEP (2008). United Nations Collaborative Programme on Reducing Emissions from Deforestation in Developing Countries. [online] available from http://www.undp.org/mdtf/UN-REDD/docs/Annex-A-FrameworkDocument.pdf accessed May 2009.

Fatoyinbo, T.E. and Simard, M. (in press 2011). Mapping of Africa's mangrove forest extent, height and biomass with ICESat/GLAS and SRTM data fusion, International Journal of Remote Sensing.

Finnish_Forest_Association (2007). More exact information on forest resources by remote sensing. Available online at:

http:/ / www.forest.fi/smyforest/foresteng.nsf/10256a7420866fd0c2256b0300248b0 d/2406c3e05b1ee4f7c22572b4002fc660?OpenDocument\&Highlight=0,laser.

Goudie, J.W. and Stearns-Smith, S. (2007). TASS-TIPSY advance growth and yield modelling in British Columbia, LINK, 8: 7-8.

GSFC (2010). Laser Vegetation Index Sensor; System design.

https:/ / lvis.gsfc.nasa.gov/index.php?option=com_content\&task=view\&id=29 (accessed May 2010).

GSFC (2011). ICESat-2. Available online at: http:/ / icesat.gsfc.nasa.gov/icesat2/index.php.

Hancock, S. (2010). Understanding the measurement of forests with waveform lidar, PhD thesis, University College London, Available online at:

http://eprints.ucl.ac.uk/20221/.

Harding, D., Dabney, P. and Valett, S. (in press 2011). Polarmetric, two-color, photoncounting laser altimeter measurements of forest canopy structure, SPIE Proceedings LIDAR and RADAR 2011, Nanjing, China.

Harding, D.J., Blair, J.B., Rabine, D.R. and Still, K. (1998). SLICER: Scanning Lidar Imager of Canopies by Echo Recovery Instrument and Product Description. NASA; June 1998.

Hollaus, M., Dorigo, W., Wagner, W., Shadauer, K., Höfle, B. and Maier, B. (2009). Operational area-wide stem volume estimation based on airborne laser scanning and national forest inventory data, International Journal of Remote Sensing, 30(19).

Huang, C., Goward, S.N., Masek, J.G., Thomas, N., Zhu, Z. and Vogelmann, J.E. (2010). An Automated Approach for Reconstructing Recent Forest Disturbance History 
Using Dense Landsat Time Series Stacks, Remote Sensing of Environment, 114: 183-198.

Huang, H., Zhang, L., Gong, P., Cheng, X., Clinton, N., Cao, C., Ni, W. and Wang, L. (2011). Automated Methods for Measuring DBH and Tree Heights with a Commercial Scanning Lidar, Photogrammetric Engineering and Remote Sensing, 77(3): 219-227.

Hurtt, G.C., Dubayah, R., Drake, J.B., Moorcroft, P.R., Pacala, S. and Fearon, M. (2004). Beyond potential vegetation: Combining lidar remote sensing and a heightstructured ecosystem model for improved estimates of carbon stocks and fluxes, Ecological Applications, 14(3): 873-883.

IPCC (2003). Good Practice Guidance for Land Use, Land Use Change and Forestry. Institute for Global Environmental Strategies (IGES) for the Intergovernmental Panel on Climate Change. [online] available from:

http://www.ipcc-nggip.iges.or.jp/public/gpglulucf_contents.html accessed May 2009.

Jenkins, J., Chojnacky, D., Heath, L. and Birdsey, R. (2003). National-Scale Biomass Estimators for United States Tree Species, Forest Science, 49(1): 12-35.

Jenkins, J., Chojnacky, D., Heath, L. and Birdsey, R. (2004). Comprehensive database of diameter-based regressions for North American tree species, United States Department of Agriculture, Forest Service. General Technical Report NE-319, pp. 145 .

Kraus, K. and Pfeiffer, N. (1998). Determination of terrain models in wooded areas with airborne laser scanner data, ISPRS Journal of Photogrammetry and Remote Sensing, 54: 193-203.

Lefsky, M. (2010). A global forest canopy height map from the Moderate Resolution Imaging Spectroradiometer and the Geoscience Laser Altimeter System, Geophysical Research Letters, 37.

Lefsky, M., Harding, D., Keller, M., Cohen, W., Carabajal, C., Del Bom Espirito-Santo, F., Hunter, M., de Oliveira Jr., R. and de Camargo, P. (2005). Estimates of forest canopy height and aboveground biomass using ICESat, Geophysical Research Letters, 32 L22S02.

Lefsky, M.A., Keller, M., Pang, Y., de Camargo, P. and Hunter, M.O. (2007). Revised method for forest canopy height estimation from the Geoscience Laser Altimeter System waveforms, Journal of Applied Remote Sensing, 1: 1-18.

Los, S.O., Rosette, J.A. and North, P.R.J. (2008). Observational evidence for links between increased drought severity and land-cover change. In: R.A. Hill, J. Rosette and J. Suárez (Editors), Proceedings of SilviLaser 2008: 8th international conference on LiDAR applications in forest assessment and inventory, Edinburgh, UK. ISBN: 978-0-85538774-7.

Los, S. O., Rosette, J. A. B., Kljun, N., North, P. R. J., Suárez, J. C., Hopkinson, C., Hill, R. A. , Chasmer, L. , van Gorsel, E., Mahoney, C. and Berni, J. A. J. (2011). Vegetation height products between $60^{\circ} \mathrm{S}$ and $60^{\circ} \mathrm{N}$ from ICESat GLAS data, Geosci. Model Dev. Discuss., 4, 2327-2363, doi: 10.5194/gmdd-4-2327-2011. 
Maltamo, M., Eerikäinen, K., Pitkänen, J., Hyyppä, H. and Vehmas, M. (2004). Estimation of timber volume and stem density based on scanning laser altimetry and expected tree size distribution functions, Remote Sensing of Environment, 90(3): 319-330.

Matthews, R.W. and Mackie, E.D. (2006). Forest Mensuration; A handbook for practioners. Forestry Commission Publications, Edinburgh.

Morsdorf, F., Meier, E., Kötz, B., Itten, K.I., Dobbertin, M. and Allgöwer, B. (2004). Lidar-based geometric reconstruction of boreal type forest stands at single tree level for forest and wildfire management, Remote Sensing of Environment, 3(92): 353-362.

Morsdorf, F., Nichol, C., Malthus, T. and Woodhouse, I.H. (2009). Assessing forest structural and physiological information content of multi-spectral LiDAR waveforms by radiative transfer modelling, Remote Sensing of Environment, 113: 2152-2163.

Næsset, E. (1997a). Determination of mean tree height of forest stands using airborne laser scanner data, ISPRS Journal of Photogrammetry and Remote Sensing, 52.

Næsset, E. (1997b). Estimating timber volume of forest stands using airborne laser scanner data, Remote Sensing of Environment, 61.

Næsset, E. (2002). Predicting forest stand characteristics with airborne scanning laser using a practical two-stage procedure and field data, Remote Sensing of Environment, 80: 8899.

Næsset, E. (2004). Accuracy of forest inventory using airborne laser scanning: evaluating the first nordic full-scale operational project, Scandinavian Journal of Forest Research, 19(6).

NASA (2010). NASA Carbon Monitoring System Initiative. Available online at: http://cce.nasa.gov/cce/cms/index.html.

Nelson, R. (2010). Model Effects on GLAS-based Regional Estimates of Forest Biomass and Carbon, International Journal of Remote Sensing, 31(5): 1359-1372.

Nelson, R., Næsset, E., Gobakken, T., Ståhl, G. and Gregoire, T. (2008). Regional Forest Inventory using an Airborne Profiling LiDAR, Journal of Forest Planning, 13(Special Issue 'Silvilaser'): 287-294.

Nelson, R., Parker, G. and Hom, M. (2003). A Portable Airborne Laser System for Forest Inventory, Photogrammetric Engineering and Remote Sensing, 69: 167-273.

Nelson, R., Ranson, K.J., Sun, G., Kimes, D.S., Kharuk, V. and Montesano, P. (2009). Estimating Siberian timber volume using MODIS and ICESat/GLAS, Remote Sensing of Environment, 113(3): 691-701.

Nelson, R., Short, A. and Valenti, M. (2004). Measuring Biomass and Carbon in Delaware Using an Airborne Profiling Lidar, Scandinavian Journal of Forest Research, 19: 500511.

Ni-Meister, W., Jupp, D.L.B. and Dubayah, R. (2001). Modeling Lidar Waveforms in Heterogeneous and Discrete Canopies, IEEE Transactions on Geoscience and Remote Sensing, 39(9): 1943-1958. 
North, P.R.J., Rosette, J.A.B., Suárez, J.C. and Los, S.O. (2010). A Monte Carlo radiative transfer model of satellite waveform lidar, International Journal of Remote Sensing 31(5): 1343-1358.

NSIDC (2010a). ICESat Laser Operation Period Attributes. Available online at: http://nsidc.org/data/icesat/docs/glas_laser_ops_attrib.xls National Snow and Ice Data Center, Colorado, USA.

NSIDC (2010b). ICESat/ GLAS Data at NSIDC, Available online at: http://nsidc.org/daac/icesat/ National Snow and Ice Data Center, Colorado, USA

Popescu, S., Wynne, R. and Nelson, R. (2003). Measuring individual tree crown diameter with lidar and assessing its influence on estimating forest volume and biomass, Canadian Journal of Forest Research, 29(5): 564-577.

Rosette, J.A.B., North, P.R.J. and Suárez, J.C. (2008). Vegetation Height Estimates for a Mixed Temperate Forest using Satellite Laser Altimetry, International Journal of Remote Sensing, 29(5): 1475-1493.

Schutz, B., Zwally, H., Shuman, C., Hancock, D. and DiMarzio, J. (2005). Overview of the ICESat Mission, Geophysical Research Letters, 32: L21S01.

Schutz, B.E. (2002). Laser Footprint Location (Geolocation) and Surface Profiles, Algorithm Theoretical Basis Document Version 3.0. NASA Goddard Space Flight Center.

Simard, M. (2011). Combining Lidar and Radar for Remote Sensing of Land Surfaces Available online at: http:/ / lidarradar.jpl.nasa.gov/index.html.

Sithole, G. and Vosselman, G. (2004). Experimental comparison of filter algorithms for bare earth extraction from airborne laser scanning point clouds, International Archives of Photogrammetry and Remote Sensing, 59: 85-101.

Suárez, J., Ontiveros, C., Smith, S. and Snape, S. (2005). Use of airborne LiDAR and aerial photography in the estimation of individual tree heights in forestry, Computers and Geosciences, 31(2): 253-262.

Suárez, J.C. (2010). An Analysis of the Consequences of Stand Variability in Sitka Spruce Plantations in Britain using a combination of airborne LiDAR analysis and models, PhD, University of Sheffield, Sheffield.

Sun, G. and Ranson, K.J. (2000). Modeling lidar returns from forest canopies, IEEE Transactions on Geoscience and Remote Sensing, 38(6): 2617-2626.

Sun, G., Ranson, K.J., Kimes, D.S., Blair, J.B. and Kovacs, K. (2008a). Forest vertical structure from GLAS: An evaluation using LVIS and SRTM data, Remote Sensing of Environment, 112(2008): 107-117.

Sun, G., Ranson, K.J., Masek, J., Guo, Z., Pang, Y., Fu, A. and Wang, D. (2008b). Estimation of Tree Height and Forest Biomass from GLAS Data, Journal of Forest Planning, 13(Special Issue 'Silvilaser'): 157-164.

Swisstopo (2011). The Federal Office of Topography (swisstopo). Available online at: www.swisstopo.ch.

Wehr, A., Lohr, U. and Baltsavias, E. (1999). Editorial: Theme Issue on Airborne Laser Scanning, ISPRS Journal of Photogrammetry and Remote Sensing, 54: 61-63.

WHRC (2011). Pan-tropical Forest Carbon Mapped with Satellite and Field Observations. Available online at: http://www.whrc.org/mapping/pantropical/modis.html. 
Woodhouse, I.H., Nichol, C., Sinclair, P., Jack, J., Morsdorf, F., Malthus, T. and Patenaude, G. (in press 2011). A Multispectral Canopy LiDAR Demonstrator Project, IEEE Geoscience and Remote Sensing Letters.

Wulder, M., Bater, C., Coops, N.C., Hilker, T. and White, J. (2008). The role of LiDAR in sustainable forest management, The Forestry Chronicle, 84(6).

Zhang, K., Chen, S., Whitman, D., Shyu, M., Yan, J. and Zhang, C. (2003). A Progressive Morphological Filter for Removing Nonground Measurements from Airborne Lidar Data, IEEE Transactions on Geoscience and Remote Sensing, 41(4): 872-882.

Zianis, D., Muukkonen, P., Mäkipää, R. and Mencuccini, M. (2005). Biomass and stem volume equations for tree species in Europe, Silva Fennica, Monographs 4: 1-63. 




\author{
Remote Sensing of Biomass - Principles and Applications \\ Edited by Dr. Lola Fatoyinbo
}

ISBN 978-953-51-0313-4

Hard cover, 322 pages

Publisher InTech

Published online 28, March, 2012

Published in print edition March, 2012

The accurate measurement of ecosystem biomass is of great importance in scientific, resource management and energy sectors. In particular, biomass is a direct measurement of carbon storage within an ecosystem and of great importance for carbon cycle science and carbon emission mitigation. Remote Sensing is the most accurate tool for global biomass measurements because of the ability to measure large areas. Current biomass estimates are derived primarily from ground-based samples, as compiled and reported in inventories and ecosystem samples. By using remote sensing technologies, we are able to scale up the sample values and supply wall to wall mapping of biomass. Three separate remote sensing technologies are available today to measure ecosystem biomass: passive optical, radar, and lidar. There are many measurement methodologies that range from the application driven to the most technologically cutting-edge. The goal of this book is to address the newest developments in biomass measurements, sensor development, field measurements and modeling. The chapters in this book are separated into five main sections.

\title{
How to reference
}

In order to correctly reference this scholarly work, feel free to copy and paste the following:

Jacqueline Rosette, Juan Suárez, Ross Nelson, Sietse Los, Bruce Cook and Peter North (2012). Lidar Remote Sensing for Biomass Assessment, Remote Sensing of Biomass - Principles and Applications, Dr. Lola Fatoyinbo (Ed.), ISBN: 978-953-51-0313-4, InTech, Available from: http://www.intechopen.com/books/remotesensing-of-biomass-principles-and-applications/lidar-remote-sensing-for-biomass-assessment

\section{INTECH}

open science | open minds

\section{InTech Europe}

University Campus STeP Ri

Slavka Krautzeka 83/A

51000 Rijeka, Croatia

Phone: +385 (51) 770447

Fax: +385 (51) 686166

www.intechopen.com

\section{InTech China}

Unit 405, Office Block, Hotel Equatorial Shanghai

No.65, Yan An Road (West), Shanghai, 200040, China

中国上海市延安西路65号上海国际贵都大饭店办公楼 405 单元

Phone: +86-21-62489820

Fax: $+86-21-62489821$ 
(C) 2012 The Author(s). Licensee IntechOpen. This is an open access article distributed under the terms of the Creative Commons Attribution 3.0 License, which permits unrestricted use, distribution, and reproduction in any medium, provided the original work is properly cited. 